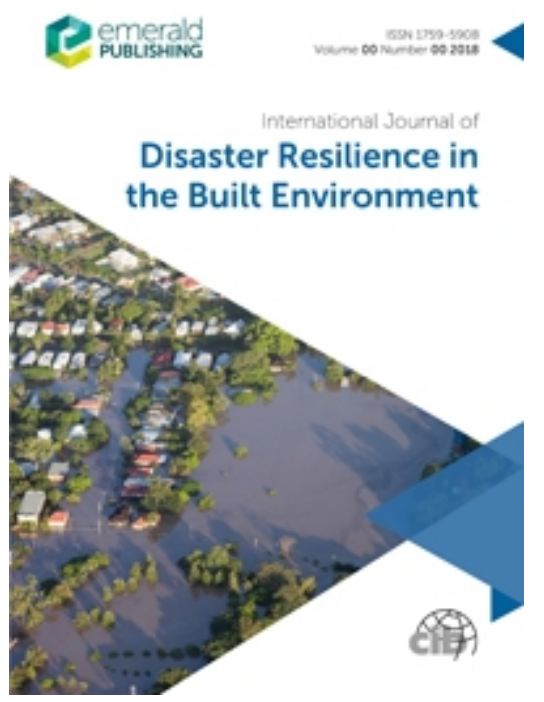

\title{
Guiding Factors for Planning Public Open Spaces to enhance Coastal Cities' Disaster Resilience to Tsunamis
}

\begin{tabular}{|r|l|}
\hline Journal: & International Journal of Disaster Resilience in the Built Environment \\
\hline Manuscript ID & IJDRBE-06-2020-0058.R2 \\
\hline Manuscript Type: & Research Paper \\
\hline Keywords: & $\begin{array}{l}\text { Built environment, Public Open Spaces, Disaster Resilience, Sustainable } \\
\text { development, Tsunami, Urban Planning }\end{array}$ \\
\hline
\end{tabular}

\section{SCHOLARONE ${ }^{\text {M }}$ \\ Manuscripts}




\title{
Guiding Factors for Planning Public Open Spaces to enhance Coastal Cities' Disaster Resilience to Tsunamis
}

\begin{abstract}
Purpose - Public Open Spaces (POS) in cities are often measured as a strength to enhance cities' sustainability with a contribution to the three pillars; economic, social, and environment. Nevertheless, the importance of POS for disaster resilience is less recognised and remains underrehearsed in the urban planning context. Within this context, this research paper investigates the methods and approaches of using POS to enhance the coastal cities' resilience to Tsunamis through planning and designing interventions.

Design/methodology/approach - The study used the grounded theory as the research strategy. Accordingly, data collection involved 72 unstructured interviews covering a wide variety of participants related to the field of study including Tsunami affected communities, disaster resilience experts, urban planners, sociologists, and coastal planners, etc. in the context of Sri Lanka. The grounded theory coding procedure is used to analyse the data which includes transcripts, notes, visual images, maps, and documents.

Findings - The analysis revealed that there is a significant potential to use POS to enhance the coastal cities' resilience to Tsunamis as an emergency evacuation directing point, as a primary place for emergency rescue, as an agent for temporary sheltering, as a facilitator for Tsunami disaster mitigation and as a mediator to provide Tsunami awareness. Finally, the findings propose five guiding factors for planning POS to enhance coastal cities' disaster resilience to Tsunamis.

Originality/value - This paper introduces an innovative and unique approach for future urban planners and design professionals, to plan and design POS with a new direction towards disaster resilience while ensuring sustainability.
\end{abstract}

Keywords Public Open Spaces, Disaster Resilience, Tsunami, Coastal cities, Urban Planning 


\section{Introduction}

The term Public open space became popular in the $19^{\text {th }}$ century in the United Kingdom and the United States with an understanding of improving the health and quality of life of the workingclass people who lived in squalid and crowded living conditions (Giles-Corti et al., 2005). Since then, there can be found different interpretations of the term Public open space. However, in this paper, Public open spaces (POS), are considered as an outdoor open space that is accessible for the public and used by the public. This includes public parks, public playgrounds, public squares, and so on. In contemporary planning, these types of POS are considered as an asset to improve the visual quality, protect natural resources, enhance recreational uses, celebrate the diversity of space, increase the social integration and add economic values to cities, etc. POS can contribute to the path of sustainability offering many benefits towards the three main pillars of sustainability; social, economic, and environment (Chiesura, 2004). However, the development of sustainability should incorporate the improvements in disaster resilience (Paton and Johnston, 2006). Yet, the potential contribution of POS for disaster resilience remains to unfold both in the research field and practice. Confirming this, Hossain (2014) states that the role of POS in increasing cities' resilience to disasters, has not been fully discovered yet.

Further, evidence-based literature identifies that there is a significant potential of using POS for disaster resilience through the integration of disaster management strategies with Urban planning strategies). According to Jayakody, Amaratunga, and Haigh (2018), the literature which focuses on emergency management and recovery, suggests that POS have the potential to be used as safe areas for emergency evacuation and to provide facilities and services within the recovery period. However, most of these discussions emphasise the potential uses, yet less consideration has been given to find out how to harness these potentials and the practical implementation of these potentials to a city context. Generally, urban planners look at the POS as a part of the built environment, and recovery planners identify open spaces as a part of the environment plan without looking at an integrated approach (Allan \& Bryant, 2010). Conversely, it is evident that emergency management plans and recovery plans become more effective when it is aligned with the everyday life of the city (Allan, Bryant, Wirsching, Garcia, \& Teresa Rodriguez, 2013). Hitherto, finding out the potentials of POS for disaster resilience and methods and approaches to harness these potentials is a research gap that needs to be filled.

However, the role of POS in disaster resilience may differ according to the type of disaster. For instance, the role of POS in flooding events is completely different from an earthquake event. Out of these various types of hazards, Tsunami is considered as an extremely destructive hazard. Historical records indicate that Tsunamis worldwide have killed hundreds of thousands of people (National Tsunami Hazard Mitigation Program, 2001). For instance, the Tsunami 2004 reminded the world to be more proactive by claiming nearly 275000 lives and destroying billions of dollars' worth properties (Barber, 2005). Recently, Indonesia was struck by Tsunamis two times within the year 2018. In September 2018, a magnitude 7.5 earthquake and tsunami killed more than 2,000 
people in Palu, the capital (WorldVision, 2019). Then, in December 2018, another Tsunami struck Java and Sumatra resulting in more than 300 deaths (WorldVision, 2019). Accordingly, these unpredictable and infrequent Tsunami events time to time remind the world, the importance of the continuous focus on making coastal areas resilient to Tsunamis.

Apart from this destructive nature of Tsunami hazard, the costal urbanization together with the rapid population growth in coastal cities increase the disaster exposure. Therefore, making coastal cities resilient to Tsunamis has become an increasingly important task. However, Tsunami is infrequent and unpredictable; it may occur after 100years or 1000years. Therefore, allocating resources with the sole purpose of preventing a disaster that may or may not happen for the next 100 or 1000 years, cannot be considered as a sustainable solution. For instance, in some cities, large quantities of unstructured open spaces left for emergency evacuation, have created issues to achieve liveable, diverse, and sustainable urban environments (Allan \& Bryant, 2010). Furthermore, it will be difficult to negotiate the need for these Tsunami disaster prevention measures when prioritising resource allocation in cities. Hence, Tsunami disaster resilience measures need to be multipurpose. Therefore, addressing the research need of 'finding out the uses of POS for disaster resilience incorporating the day-to-day uses of the cities' to Tsunami prone coastal cities context can be considered as a significant and critical research need. With the identification of this research need, this study focused on finding out the potential uses of POS for tsunami disaster resilience and methods to incorporate these potentials into the everyday life of the city.

Furthermore, this study was focused on the Sri Lankan context and the selection was done due to three main reasons. The first reason is Sri Lanka is one of the Tsunami prone countries located in the Indian ocean, and the 2004 Tsunami was one of the worst disasters ever recorded in Sri Lankan history. Secondly, as pointed out by UN-Habitat (2016), approximately $80 \%$ of national economic infrastructure and $70 \%$ of the urban population is concentrated in coastal cities and cities in disaster-prone areas in Sri Lanka. Hence, any adverse effect on the coastal urban centers will affect significantly to the country's national economy and the social setting. Thirdly, despite these vulnerabilities, the built-up area is increasingly expanding in coastal cities mostly through unplanned development activities which further increases the disaster risk in coastal cities, Sri Lanka. Therefore, it is inevitably essential to find out the strategies to improve the resilience of coastal cities in Sri Lanka to Tsunamis. With the consideration of all these factors, this study focuses on finding out the potential uses of POS to enhance the coastal cities resilience to Tsunamis and methods to harness the identified potentials in the context of Sri Lanka.

\section{Methodology}

This paper is based on the part of the findings of a doctoral study that aimed to 'develop a framework to plan and design public open spaces as a strategy to enhance coastal cities' resilience to tsunamis in Sri Lanka'. After careful consideration of all the possible research strategies, the 
researchers selected the 'Grounded theory' as the research strategy based on a few key reasons. Mainly the role of POS as a strategy for Tsunami disaster resilience has not been fully discovered and poorly understood within the existing literature. Therefore, further exploration was needed to increase the existing understanding. The usage of grounded theory brought unique benefit to this study through its ability to generate an explanatory theory reflecting the complexity and the variability of the research covering study fields such as coastal planning, disaster resilience, urban planning, and urban design.

Accordingly, based on the open mind approach of the grounded theory method, the study mainly used unstructured interviews for data collection. 72 interviews were conducted including the community who were affected by the 2004 Tsunami and both practitioners and academics in the fields of urban planning, coastal planning, disaster resilience, sociology, and civil engineering in the context of Sri Lanka. The breakdown of the interview groups conducted during the study is presented in table $\mathrm{i}$.

\begin{tabular}{|l|c|}
\hline \multicolumn{1}{|c|}{ Categories of Participants } & $\begin{array}{c}\text { No. of } \\
\text { Interviews }\end{array}$ \\
\hline Disaster Management Experts & 9 \\
\hline Urban Planners & 9 \\
\hline Coastal Planners & 5 \\
\hline Civil/Structural Engineers & 2 \\
\hline Sociologists & 2 \\
\hline Community- Batticoloa & 15 \\
\hline Community- Galle & 15 \\
\hline Community- Hambanthota & 15 \\
\hline Total & $\mathbf{7 2}$ \\
\hline
\end{tabular}

Table i: Summary of the interviews conducted

Apart from the interviews, documents, maps, and visual images related to the interview discussion were reviewed as the secondary method. The data was analysed concurrently to the data collection through the grounded theory data analysis procedure. The constant comparative analysis method is used for the analysis. The analysis process commenced with first sorting the data into properties and categories, conducting sentence-by-sentence analysis, and breaking the data into distinctive units which is called open coding. Then through the axial coding, the data were put back together in a new form by stitching them together or by making connections between the categories. The final stage of the analysis which is called selective coding was used to identify the core categories, which are presented as guiding factors in this paper. Once these core categories/guiding factors are selected, other subcategories and properties were systematically connected to the core, validating the relationships. Finally, in order to validate the findings and to check the transferability of the 
research findings to the broader context within Sri Lanka was checked by interviewing 6 experts in the field.

Accordingly, the findings of the overall study contained two parts. The first part contains guiding factors to plan and design POS for Tsunami disaster resilience and the second part provides a planning and designing framework based on the identified guiding factors. Accordingly, this paper presents the first part of the findings which are the guiding factors to plan and design POS for Tsunami disaster resilience.

\section{Findings}

The findings of this study revealed that there is a significant potential of using POS for Tsunami disaster resilience. The POS in coastal cities have the ability to act as an emergency evacuation directing point, as an agent for emergency evacuation distribution, as a primary place for emergency rescue, as a facilitator for Tsunami disaster mitigation, and as a mediator to provide Tsunami awareness.

However, the use of these potentials and the effectiveness of harnessing these potentials are determined by five main factors. Therefore, these five factors are identified as five guiding factors that can be used as guiding factors when planning and designing POS for Tsunami disaster resilience. Accordingly, potential uses of POS to enhance the coastal cities resilience to Tsunamis and methods to harness the identified potentials can be presented through the introduction of five guiding factors as follows.

\subsection{Risk Zonation guides the locations of POS and the benefits involved}

The analysis informed that POS can mainly contribute to emergency evacuation plans in three ways. Firstly, POS can act as an emergency evacuation directing place to direct evacuees towards the right direction through a landmark system and using design features in POS as landmarks. Secondly, as a place to distribute people to safe places through the use of vehicles in evacuation. Thirdly, as a safe place for emergency gathering through the design with more space.

However, these three types of uses of POS will be determined by the place where the POS is located within the Tsunami risk zonation. To use large scale POS as an emergency gathering point such POS needs to be located out of the Tsunami risk zone. Further, to use POS as a distribution place such POS needs to be located at least within Tsunami moderate risk or low-risk zone. For the reason that locating distribution places within Tsunami high-risk zone can be too dangerous considering the permitted time for evacuation and the distance to the safe zone.

In contrast, if the time permits and if there is a short distance from Tsunami high-risk zone to the safe zone such POS may have a potential even to use as a distribution place with improved access. Further, all the types of POS within the Tsunami high or moderate risk zones can be used to direct 
people towards the safe zone through a landmark system and using design features as landmarks. Accordingly, it can be understood that Tsunami risk zonation guides the places for POS and the benefits involved in emergency evacuation planning.

Further, findings informed that POS can contribute to mitigate the Tsunami risk in two ways. One method is by lowering the population density through allocating more POS within the hazardprone areas. The second method is the use of design features and the orientation of the POS to slow down and regulate the wave. Further, natural elements such as sand dunes and vegetation can be incorporated as design features to slow down and regulate the wave. This type of method encourages protecting natural elements in coastal areas benefiting many other factors such as a resilient barrier to wind and wave, coastal water intrusion and benefits of greenery, and so on. Accordingly, these two types of mitigation related uses of POS need to be guided by the risk zonation as the allocation of POS within the Tsunami risk area can be used to reduce the Tsunami risk by lowering the exposure and POS located within the Tsunami risk areas can be used to slow down and regulate the wave.

Furthermore, this type of allocation of POS will also bring many benefits to disaster risk-sensitive urban planning. Besides, the interviews conducted with disaster management practitioners in Sri Lanka pointed out that spatial planning in Sri Lanka is not well linked with the disaster risk reduction (DRR) strategies and instead DRR is considered mostly at the vision-mission statements of the urban development plans and lacking at the strategies and action project level. Therefore, this type of approach will be a good example of linking DRR with spatial planning at both macrolevel planning and micro-level designing. In summary, the points discussed in section 3.1 can be illustrated as follows (Figure 1). 


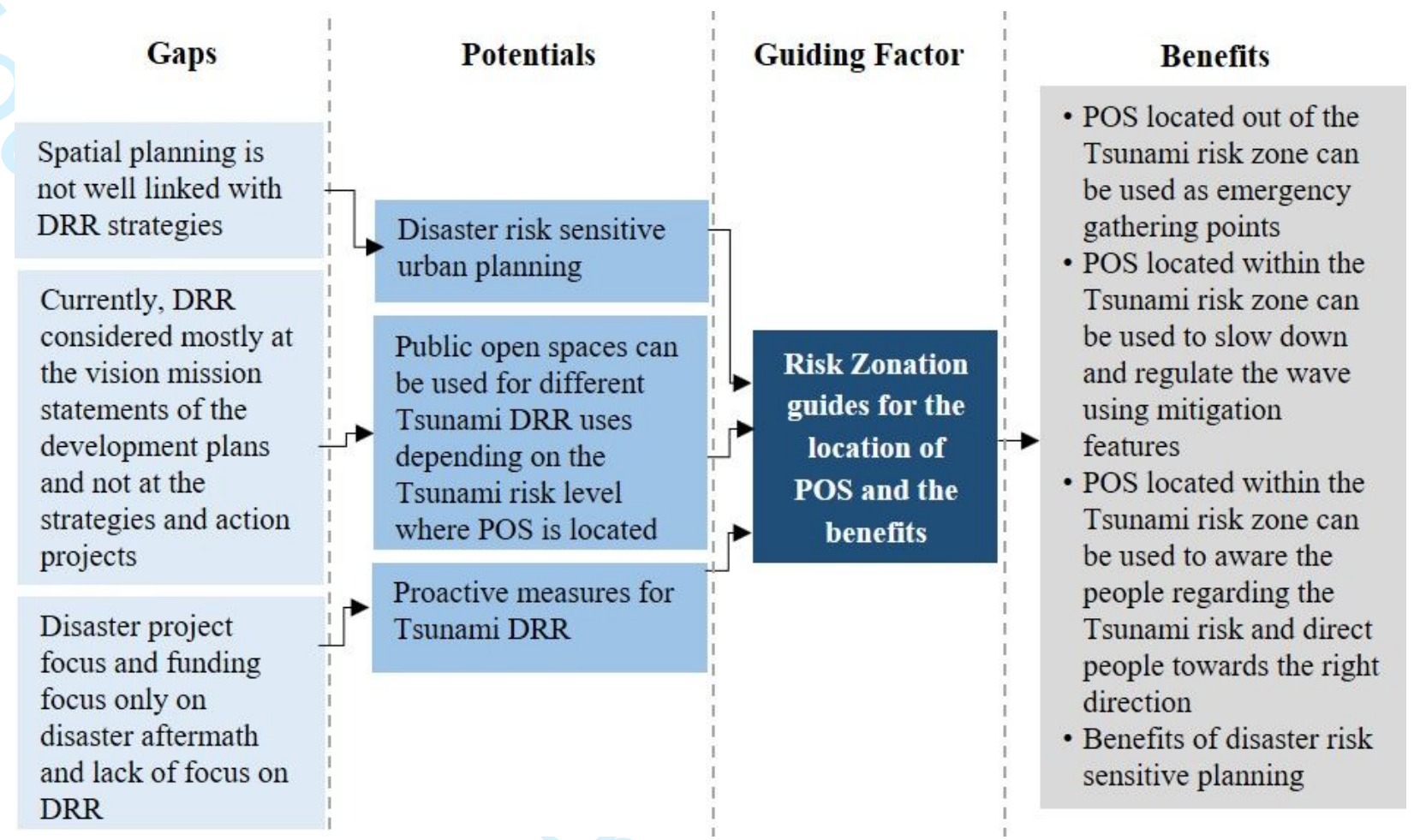

Figure 1: Risk Zonation guides the location of POS and the benefits involved

\subsection{Terrain quality and the Topographic characters guided allocation}

Section 3.1 discussed the factors related to Tsunami risk zonation. Risk zonation is different from hazard zonation. Hazard is characterized by its location, intensity or magnitude, frequency, and probability (UNISDR 2017). Risk is calculated through the multiplication of Hazard with the Vulnerability $(\mathrm{R}=\mathrm{H} \times \mathrm{V})$. Therefore, Risk calculation requires knowledge of the tsunami source, the wave propagation and subsequent inundation, geographical conditions of the affected area, and social and economic aspects (Jelínek et al. 2009). Accordingly, basic terrain quality and the topographic characters are already considered at the risk zonation. Further, risk zonation and its relationship with POS was already discussed in section 3.1.

However, findings rationalised that terrain quality and the topographic characters need to be considered as a separate factor when allocation POS for Tsunami disaster resilience at three instances. The first instance is if the area is below mean sea level or if the flat terrain continuous for several kilometers and if there is a long distance to mountainous terrain instead of allocation of vertical evacuation shelters to shorten the evacuation time, there is a possibility of allocating POS on the artificially elevated platforms. This can even be a Tsunami mound that absorbs the devastating energy of the Tsunami wave but necessarily there should be POS on top facilitating as a safe evacuation area. In this way, POS on artificially elevated platforms can contribute to the Tsunami disaster mitigation and emergency evacuation in an event of Tsunami. At the same time, in the everyday life of the city, it can be used as a public space with increased visibility of the sea. 
The second instance is when the area is below the mean sea level and the terrains sloping inward the inland, it increases the speed of the Tsunami wave. In such a context, landscape treatments such as earth bunds can be incorporated into the POS design to break the speed of the wave as a mitigation feature. The third instance is if there is mountainous terrain located near to POS these highlands can be connected with the design of POS which increases the attractiveness of the POS and also can be used for safe evacuation in the Tsunami event for the people who gathered in POS. In this way, adjacent mountainous terrain needs to be taken into consideration when designing POS for tsunami resilience as it will make sure the provision of adequate emergency evacuation places to the public in POS. Accordingly, Terrain quality and the Topographic characters of the area need to be considered as a separate factor when planning and designing POS for Tsunami disaster resilience. Important features discussed in section 3.2 can be summarised as follows.

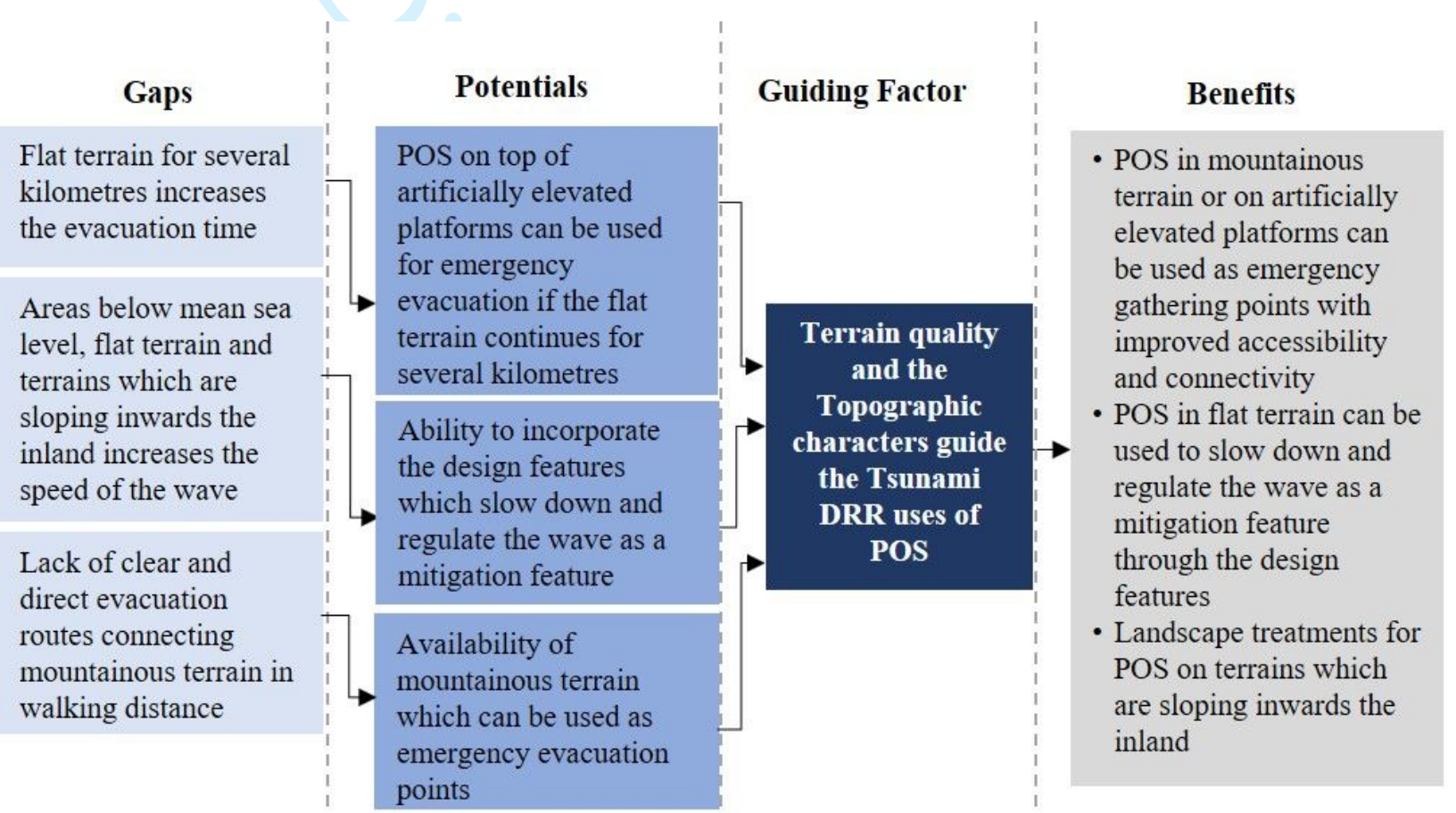

Figure 2: Terrain and Topographic characters guided allocation

\subsection{Location and Size of POS determine the DRR uses}

The third core principle is the location and size of POS which also contribute to determining the DRR uses of POS. This core principle, especially the location overlaps with the other two guiding factors which were already introduced in sections 3.1 and 3.2. Nevertheless, the location factor needs to be considered as a separate element especially when providing the Tsunami awareness. This may appear to be contradicting the relationship between the location and the public awareness. Though the awareness needs to be placed at the preparation stage of the disaster cycle, public awareness needs to be given on all the stages of the disaster cycle which means awareness on preparation, response, recovery, and awareness on mitigation. 
The analysis informed that Tsunami DRR awareness in Sri Lanka is lacking in three main areas. One is the most commonly known lack of awareness on Tsunami evacuation routes and safe evacuation points. Most people in the coast still depend on the 2004 Tsunami experience where they believe they can survive using the same old method without considering the changes of the circumstances of the next Tsunami; the height of the next wave, time of arrival, changes occurred over the time since 2004 and so on. As a solution, findings suggest without solely depending on mock drills and awareness programs, POS can be used to provide awareness on evacuation plans in the day-to-day life of the city dwellers by displaying the evacuation maps, information boards, and signboards at the POS. Considering budget restrictions to allocate money for training programs covering all the coastal population in hazard areas and the practicality of especially city dwellers being available for training events, this is a good method as after the initial cost of installation there will be a minimum cost of maintenance and the awareness will be given in every day and anytime for all the visitors. However, the quality of the display, easy to understand, and attractiveness need to be considered when designing the displays. Further, this type of information can be displayed at any POS situated within the evacuation road network.

The second type of awareness is needed where most of the people are reluctant to be prepared for the next Tsunami and do not understand the importance of proactive. This main mainly because of two reasons. One reason is, some people believe that the next Tsunami will not happen any sooner, and believe this type of hazard will occur with a gap of $100 \mathrm{yrs}$ or $200 \mathrm{yrs}$. Another reason is most people have forgotten the last Tsunami and therefore the importance of being proactive. Due to these reasons, there is a need to remind people about the destruction caused by the last Tsunami and the importance of being pro-active and prepared. In this instance, it was identified that the design features of POS can be used as a mode to remind Tsunami e.g. Sculptures and the importance of being pro-active e.g. information board.

Further, the location factor is important when selecting POS to locate these types of design features. Findings suggest that the POS located in beach areas are the best places to remind people about the Tsunami and the importance of being pro-active. For instance, locating a Tsunami related sculpture inland is not effective though it is within the hard zone, and locating it on the beach with the visibility of the sea effectively reminds people of the destruction of Tsunami and the urge of being proactive and prepared for Tsunami.

The third type is the lack of awareness on the importance of natural features related to Tsunami disaster mitigation. Therefore, people do not protect the natural features such as sand dunes, mangroves, and coastal vegetation which can act as a bio shield for Tsunami mitigation. Therefore, there is a significant need of protecting Tsunami mitigation related to natural features and at the same time to aware people on the importance of mitigation. As a solution, findings suggest that POS in beach areas can be used to install and display the tsunami mitigation related features providing awareness on the importance of them. Through this method, people will get the awareness in their day-to-day life through effective visual communication. Accordingly, it can be 
understood the importance of considering the location factor when installing the Tsunami DRR awareness related design features.

Apart from the location factor, the size or the scale of the POS is important when using POS Tsunami disaster resilience. POS in cities are available in different sizes varying from small pocket parks, medium-sized activity squares to large scale parks and public playgrounds. Depending on the location and size of POS, POS in coastal cities can be used for different purposes in an emergency evacuation. As discussed in section 3.1, POS can mainly contribute to the emergency evacuation plan in three ways and the importance of the location of the POS within the Tsunami risk zonation was already discussed in that section. Considering the size of the POS, POS located in Tsunami high-risk areas can be used as an emergency evacuation directing place utilizing POS in any size.

However, to use POS as a place to distribute people to safe places such POS need to be considerably bigger than the pocket parks and small activity squares, as this type of POS should provide an initial gathering place especially for disabled and aged people around and then need to be well linked with the road network to use the vehicles in transportation. The third type of use, which is to use as a safe place for emergency gathering, such POS needs to be large in scale to accommodate a large amount of population for a shorter period till they move to safe shelters. When allocating space for emergency gathering, more space needed for emergency gathering than the space for sheltering, because not every evacuee need shelters as some of the evacuees are visitors, commuters, residents who can go back to their house if it is not affected and people who have the capacity to find alternative accommodation such as hotels and relatives place. Therefore, more space is needed for emergency gathering and once all the people were taken out of the hazard zone they can be distributed to safe shelters within the immediate recovery period.

Further, when allocating POS for emergency gathering purpose such POS need to be large in scale and minimal physical development needs to be taken on the POS allowing more space to operate as a loose space. Accordingly, the size of the POS is important when facilitating the emergency evacuation plan. The location factor is important when using POS for both emergency evacuation and public awareness. 


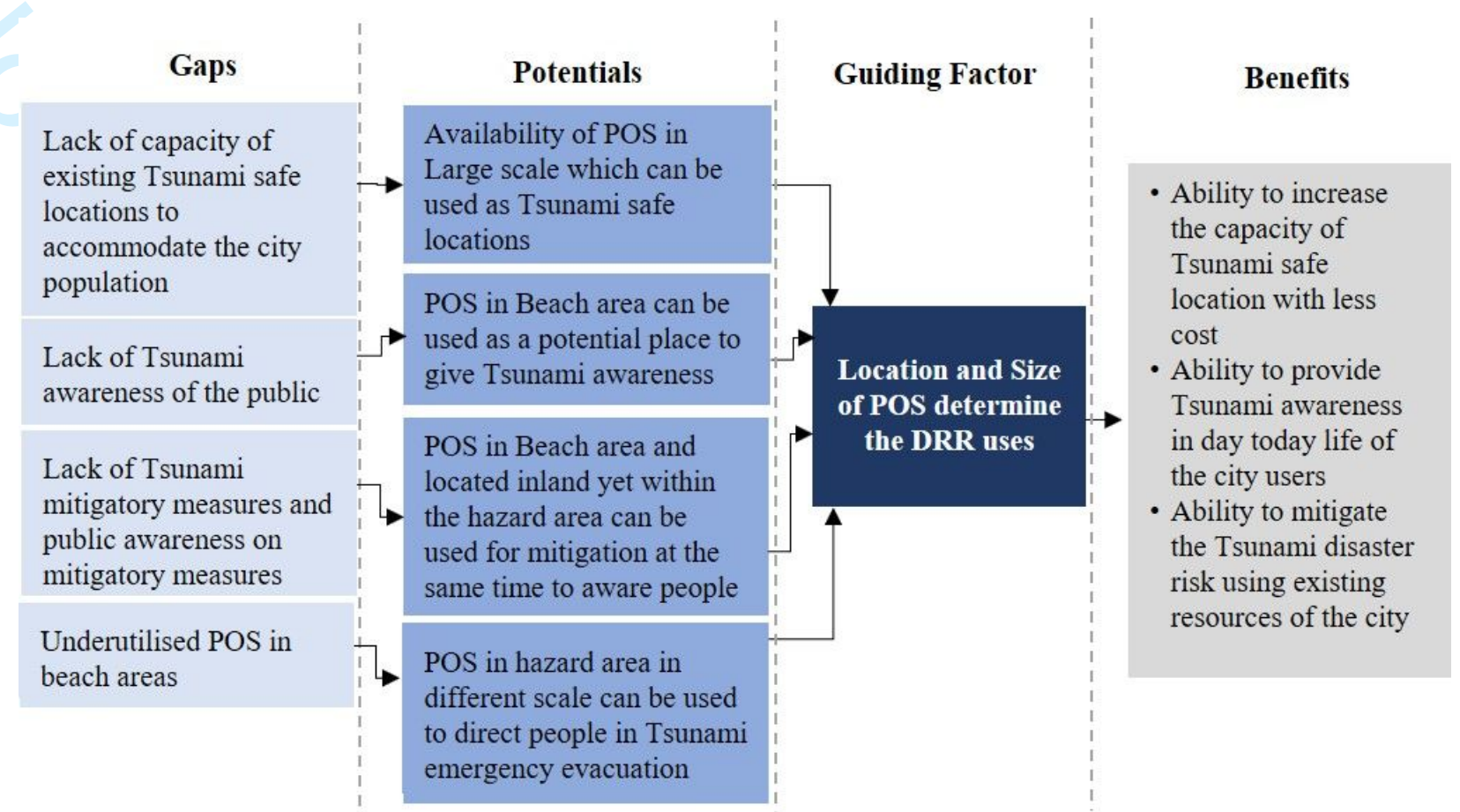

Figure 3: Location and Size of POS determine the DRR uses

\subsection{Multipurpose uses of POS}

Three guiding factors that were discussed up to now, pointed out three main potentials of POS for Tsunami disaster resilience; emergency evacuation, mitigation, and public awareness. However, all these uses are Tsunami disaster focused uses. Apart from that, findings suggest that allocating space and resources focusing on the sole purpose of Tsunami disaster resilience would not be a sustainable solution because of two reasons. Firstly, Tsunami is an infrequent and unpredictable disaster that may or may not occur for the next 100 or 200 years. Therefore, if the space is allocated for the only purpose of Tsunami resilience, in the long run, such space will get abundant and will be a threat to sustainable development. Relating this matter with the highlighted points of the literature review, it was identified that, with reference to some earthquake planning strategies, large quantities of unstructured open spaces left for emergency evacuation in cities, have created issues to achieve liveable, diverse, and sustainable urban environments (Allan \& Brytan, 2010). Applying the same principle to the Tsunami planning strategies and relating this matter with the findings, if POS are allocated for the sole purpose of Tsunami resilience, in the long run, such space will get abundant and will be a threat to sustainable development. For example, allocating large quantities of open spaces only for emergency evacuation gathering results in these places will get abundant in the long run and will welcome illegal activities in cities. Further, such areas will not be identified by the public in an emergency. Or else, to protect these places, there will be a huge cost of maintenance. 
The second reason is, when prioritising the needs of the city, if the resources are allocated for the sole purpose of Tsunami resilience, it will be difficult to negotiate the necessity of these resources with the other priorities such as economic growth, recreational uses, and tourism needs. In some instances, with the limited funds and growing demands of cities, Tsunami DRR focused projects are less prioritised. Moreover, it is evident that most of the projects were initiated when the Tsunami happened in 2004, Sri Lanka. Then with the time, the importance is diminished. Therefore, most of the projects which started soon after the Tsunami do not operate in the long term.

Further, this is a common scenario when the projects are planned for the sole purpose of Tsunami. When Tsunami DRR interventions are taken as a separate element without linking to the other development projects, it becomes difficult to negotiate the need of the project with other priorities of the city. Therefore, Tsunami DRR focused interventions need to be multipurpose. Applying the same theory to POS related uses for Tsunami disaster resilience, if the POS or the resources within the POS are allocated for the sole purpose of Tsunami, as above discussed, it is hard to implement and maintain in the long run. This fact emphasises the need for multipurpose POS catering both Tsunami resilience and the everyday life of the city.

Furthermore, in cities land is a scares resource, and allocating open spaces for mitigation or emergency evacuation is too difficult with the growing demands of the urbanization. Therefore, there is a need to get the maximum use of the available open spaces. In addition, POS can address various demands of the city economic, social and environmental. Hence, the resources and the space in POS which are allocated for tsunami disaster resilience need to be used for multipurpose rather than just for Tsunami disaster prevention. Further, open spaces are needed for the built fabric because of many reasons such as to retain fire spread, for fire evacuation, and so on. These types of various needs of the city should be considered when planning and designing POS for Tsunami resilience.

Accordingly, multipurpose POS contributing both urban resilience and disaster resilience will ensure the effective use of space and resources while strengthening the Tsunami disaster resilience in cities, negotiating the disaster management demands amongst the other demands of the city, welcoming diverse uses to the POS in cities and therefore, offering many economic, social and environmental benefits to the city. In summary, the emergence of these guiding factors can be presented as follows (Figure 4). 


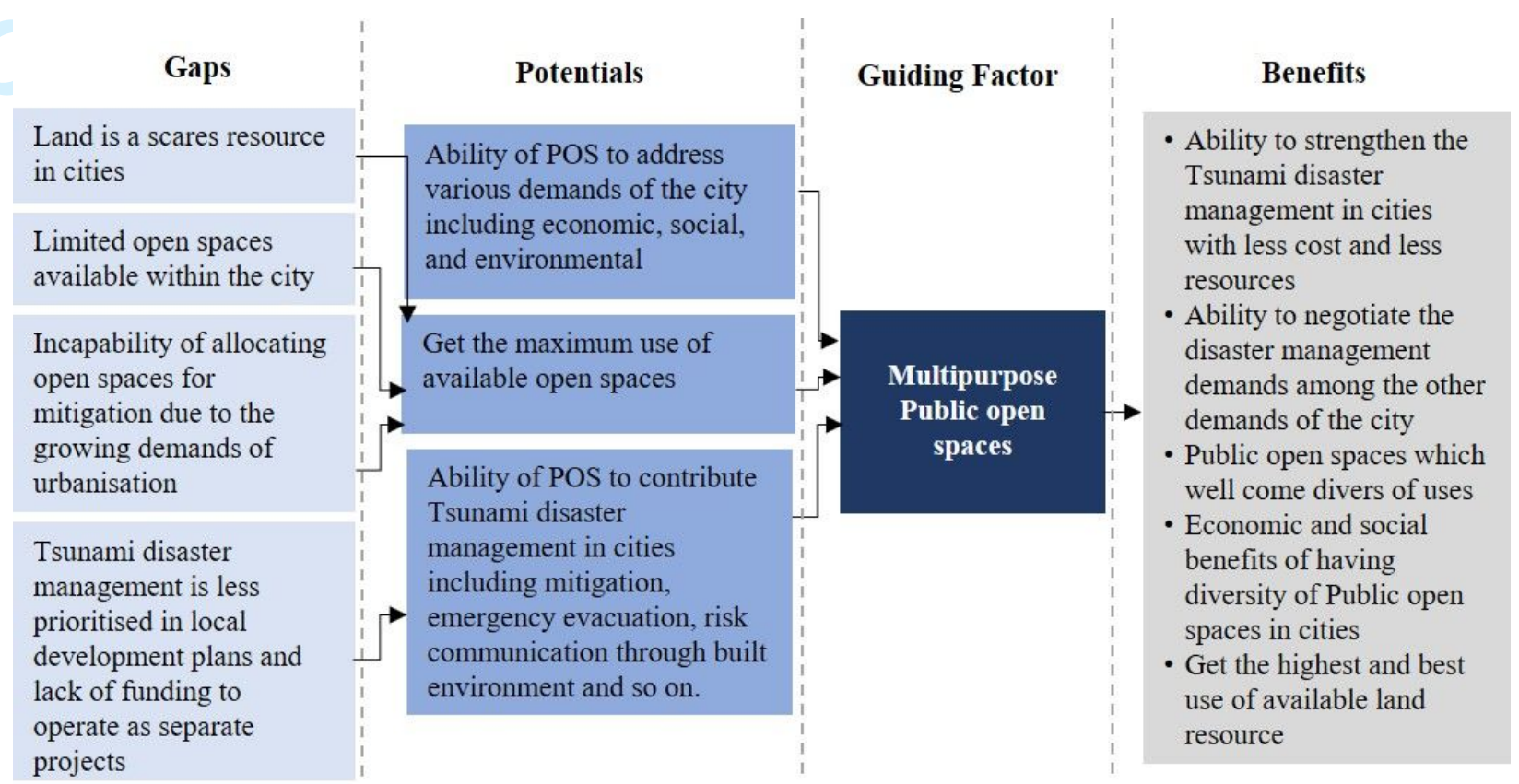

Figure 4: Multipurpose uses of POS

\subsection{Networking POS works as a DRR passage}

As discussed above, depending on the location, size, Tsunami risk zonation, terrain quality, different POS can be used for different types of uses in Tsunami disaster resilience. Further, considering the effectiveness of the use and the practical implementation in the city context, such POS needs to be used for multiple uses benefiting both urban resilience and disaster resilience. However, instead of harnessing these potentials of POS in isolation, the fifth core principle suggests connecting these POS in cities as a network that can bring further benefits to both urban resilience and Tsunami disaster resilience.

In terms of urban resilience, networking POS in cities benefits the sustainability of cities in many ways. The POS which are not located within the public footfall areas get underutilised and result in social problems such as antisocial behaviour and crimes. Further, the network of POS improves the connectivity and functionality of the city. Interconnected POS with better access to attractive large public open spaces encourage the walkability and physical activities of the people which can potentially contribute to the health of residents (Giles-Corti et al. 2005). The network of open spaces can act as a social space by offering the places to relax, to enjoy the urban experience, for a range of different activities (Thompson, 2002). Likewise, the network of POS brings many social, economic, and environmental benefits to the city's urban resilience.

In terms of making cities resilient to Tsunami disaster, the research findings suggest that a network of POS in coastal cities have the potential to work as a DRR passage. However, in order to work as a DRR passage, the previously discussed three types of POS which facilitate the emergency 
evacuation plan need to be arranged in a special way. The three types of POS in the evacuation plans are POS as an emergency evacuation directing point, POS as an emergency evacuation distribution place, and POS as a safe place for emergency evacuation gathering.

In order to work as a DRR passage, these three types of POS need to be interlinked with clear and direct road network which work as an evacuation road network. When developing this evacuation route network two factors need to be considered in the Sri Lankan context. The first factor is, currently in many parts of coastal cities in Sri Lanka there is a law of having beach access road for every 500 meters, mainly with a focus on improving the access to the beach. However, this is a good source to start the evacuation road network from the beach and these straight paths need to be linked with the local evacuation road network linked with POS. Introducing straight pathways linking the beach with local road networks can bring many benefits to the city such as improve access to the beach, facilitate evacuation, windmill effect cooling the hot tropical coastal cities, improve walkability, etc. The second factor is, this network can be used to promote horizontal evacuation, yet the network needs to be linked with vertical evacuation shelters where necessary, especially when there is a higher population density or when there is a long distance to higher grounds.

Through the development of an evacuation road network linking beach access roads and local evacuation road network with POS, can facilitate the evacuation plan in several ways as follows.

- Ability to use signboard system linked with evacuation routes network and the safe places

- Ability direct people in the right direction and distribute people among the safe location

- $\quad$ Benefits of improved access to the beach and other multipurpose use while providing adequate evacuation routes

- $\quad$ Ensure smooth evacuation flow with the improved connectivity and avoid congestions

- Ability of aware people on evacuation in their day-to-day life as the network will be used in the everyday life of the city.

- Ability to promote horizontal evacuation and discourage the use of vehicles in evacuation through a better-connected pedestrian road network.

In summary, the emergence of this core principle can be illustrated as follows (Figure 5). 


\section{Conclusions}

The urban planning and designing in cities can act in multiple ways contributing to sustainability and resilience. However, most urban planning and designing researches and disaster resilience researches follow two different paths with less integration. Accordingly, this research bridges the two research domains and attempts to integrate the urban planning research domain and disaster resilience domain. In conclusion, the research findings suggested that POS in coastal cities can play a key role when enhancing cities' resilience to Tsunami through its' ability to act as an emergency evacuation directing point, as an agent for emergency evacuation distribution, as a primary place for emergency rescue, as a facilitator for Tsunami disaster mitigation and as a mediator to provide Tsunami awareness.

Further, to harness these potentials, this paper suggests five guiding factors that can be used when planning and designing POS as a strategy to enhance coastal cities' resilience to Tsunamis. Those five guiding factors are as follows.

1. Risk Zonation guides the location of POS and the benefits involved

2. Terrain quality and the Topographic characters guided allocation

3. The location and size of POS determine the DRR uses

4. Multipurpose uses of POS

5. Networking POS works as a DRR passage

Accordingly, considering the practical implication, the findings suggested that when planning and designing POS as a strategy for tsunami disaster resilience, such strategies need to be well-aligned 
with the everyday life of the city. Further, this paper contributes to the practice by introducing a novel approach to plan and design POS as a strategy to enhance coastal cities' resilience to tsunamis in Sri Lanka. For the reason that the analysis is developed closely related to the data in the real-world context, the findings can be used as a guideline for the urban planners and urban designers when planning and designing POS to enhance coastal cities' resilience to Tsunamis. Apart from the urban planning and development practitioners, the proposed guiding factors will also benefit local government bodies to improve their local plans towards Tsunami disaster resilience. Especially in the Sri Lankan context, spatial planning is not well linked with the DRR strategies. Instead, DRR is considered mostly at the vision-mission statements in local plans and lacking at the strategies and action project level. Therefore, by following these guiding principles, local government bodies can link the DRR strategies to the POS related action projects at the local level.

The proposed framework will benefit the policymakers in Sri Lanka when preparing policies related to POS. For instance, the current policy UDA policy guide for PORS- Public open recreational space (UDA, 2018), consider the accessibility as the main requirement for selecting a public open recreational space. Adding to this, policymakers can refer to the findings of this study to set out the requirements for selecting POS in coastal cities for Tsunami disaster resilience. Furthermore, as the research was conducted in the context of Sri Lanka, the findings are directly related to the city context of Sri Lanka. However, as these five guiding factors cover a broad area, the findings may also be adapted to a different context with a careful consideration of geographic, social, economic, and environmental conditions and specifically the development pattern of the area.

\section{References}

Allan, P., Bryant, M., Wirsching, C., Garcia, D., \& Teresa Rodriguez, M. (2013). The influence of urban morphology on the resilience of cities following an earthquake. Journal of Urban Design, 18(2), 242-262.

Allan, P., \& Brytan, M. (2010). The critical role of open space in earthquake recovery: a case study. Paper presented at the EN: Proceedings of the 2010 NZSEE Conference (2010, Nueva Zelandia).

Barber, B. (2005). Tsunami relief. US Agency for International Development, Washington DC.

Chiesura, Anna. (2004). 'The role of urban parks for the sustainable city', Landscape and Urban Planning, 68: 129-38.

Giles-Corti, Billie, Melissa H Broomhall, Matthew Knuiman, Catherine Collins, Kate Douglas, Kevin Ng, Andrea Lange, and Robert J Donovan. (2005). 'Increasing walking: how important is distance to, attractiveness, and size of public open space?', American journal of preventive medicine, 28: 169-76. 
Hossain, Nasreen. (2014). 'Street'as Accessible Open Space Network in Earthquake Recovery Planning in Unplanned Urban Areas', Asian Journal of Humanities and Social Sciences (AJHSS), 2.

Jayakody, RRJC, Amarathunga D, and R Haigh. (2018). 'Integration of disaster management strategies with planning and designing public open spaces', Procedia Engineering, 212: 95461.

Jelínek, Róbert, Sandra Eckert, Gunter Zeug, and Elisabeth Krausmann. (2009). 'Tsunami vulnerability and risk analysis applied to the city of Alexandria, Egypt', JRC scientific and technical reports, Italy Google Scholar.

National Tsunami Hazard Mitigation Program. (2001). Designing for Tsunami: Seven Principles for Planning and Designing for Tsunami Hazards. http://nthmphistory.pmel.noaa.gov/Designing_for_Tsunamis.pdf

Paton, Douglas, and David Moore Johnston. (2006). Disaster resilience: an integrated approach. Charles C Thomas Publisher.

Saunders, Lewis, P., \& Thornhill, A. (2016). Research Methods for Business students (Seventh edition ed.). Harlow: Pearson Education.

Taubenböck, Hannes, Nils Goseberg, Neysa Setiadi, Gregor Lämmel, Florian Moder, Martin Oczipka, Hubert Klüpfel, Roland Wahl, Torsten Schlurmann, and Günter Strunz. (2009). "' Last-Mile" preparation for a potential disaster-Interdisciplinary approach towards tsunami early warning and an evacuation information system for the coastal city of Padang, Indonesia', Natural Hazards and Earth System Science, 9: 1509-28.

Thompson, Catharine Ward. (2002). 'Urban open space in the 21st century', Landscape and Urban Planning, 60: 59-72.

UDA. (2018). Public Outdoor Recreation Space: PORS-Urban Areas-Sri Lanka. Urban Development Authority Retrieved from http://www.uda.gov.lk/attachments/regulations/pors_urban_areas.pdf

UN-Habitat. (2016). 'Disaster Resilient City Development Strategies for Sri Lankan Cities', Accessed 29/10/2016. http://www.fukuoka.unhabitat.org/projects/sri_lanka/detail20_en.html.

UNISDR. (2017). 'TERMINOLOGY ON DISASTER RISK REDUCTION', Accessed 01.09.2018. https://www.unisdr.org/we/inform/terminology.

World Vision. (2019). 2018 Indonesia quakes and tsunamis. Retrieved from https://www.worldvision.org/disaster-relief-news-stories/2018-indonesia-earthquake-facts 


\begin{tabular}{|l|c|}
\hline \multicolumn{1}{|c|}{ Categories of Participants } & $\begin{array}{c}\text { No. of } \\
\text { Interviews }\end{array}$ \\
\hline Disaster Management Experts & 9 \\
\hline Urban Planners & 9 \\
\hline Coastal Planners & 5 \\
\hline Civil/Structural Engineers & 2 \\
\hline Sociologists & 2 \\
\hline Community- Batticoloa & 15 \\
\hline Community- Galle & 15 \\
\hline Community- Hambanthota & 15 \\
\hline Total & $\mathbf{7 2}$ \\
\hline
\end{tabular}

Summary of the interviews conducted $176 \times 132 \mathrm{~mm}(150 \times 150 \mathrm{DPI})$ 


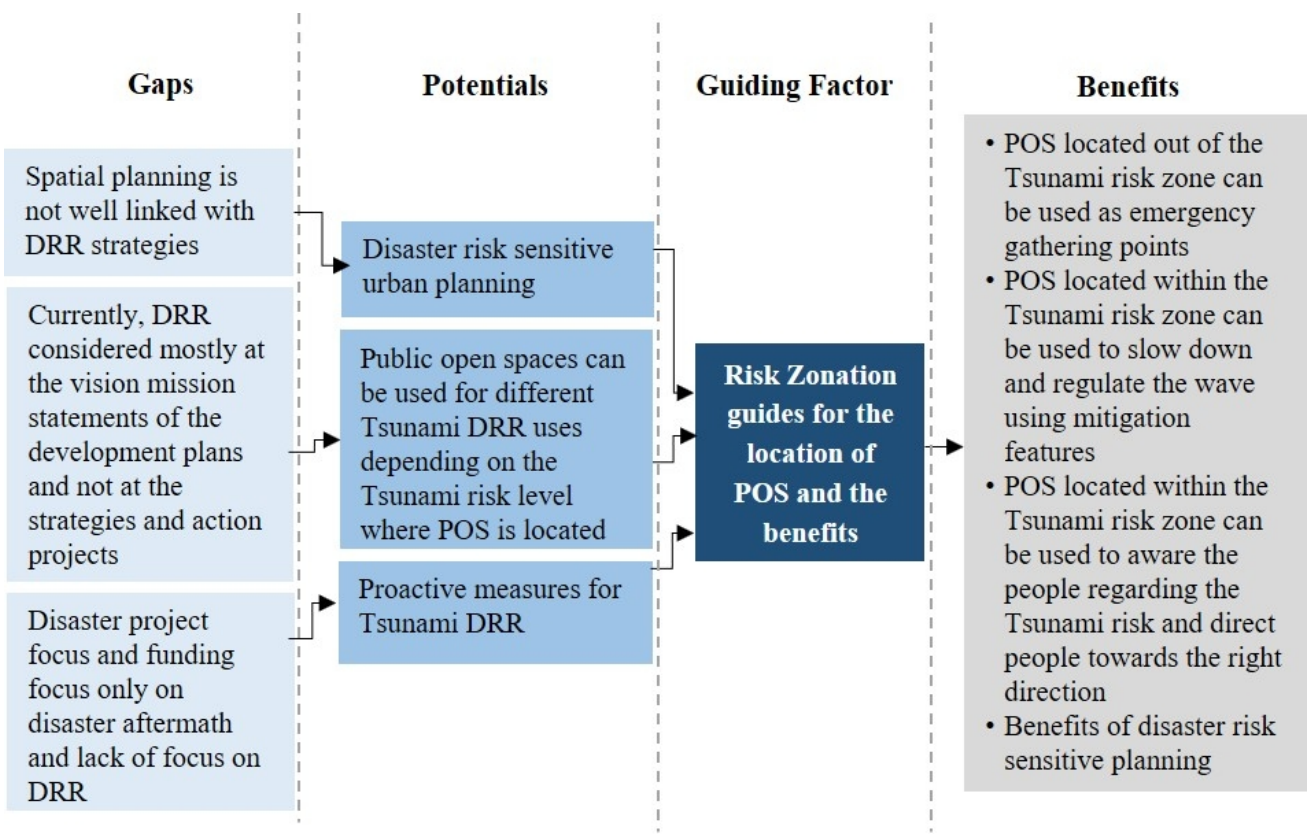

Risk Zonation guides the location of POS and the benefits involved

$160 \times 101 \mathrm{~mm}(150 \times 150 \mathrm{DPI})$ 


\begin{tabular}{|c|c|c|c|}
\hline Gaps & Potentials & \multirow{2}{*}{ Guiding Factor } & Benefits \\
\hline $\begin{array}{l}\text { Flat terrain for several } \\
\text { kilometres increases } \\
\text { the evacuation time }\end{array}$ & \multirow{2}{*}{$\begin{array}{l}\text { POS on top of } \\
\text { artificially elevated } \\
\text { platforms can be used } \\
\text { for emergency } \\
\text { evacuation if the flat } \\
\text { terrain continues for } \\
\text { several kilometres }\end{array}$} & & $\begin{array}{l}\text { POS in mountainous } \\
\text { terrain or on artificially } \\
\text { elevated platforms can } \\
\text { be used as emergency }\end{array}$ \\
\hline $\begin{array}{l}\text { Areas below mean sea } \\
\text { level, flat terrain and } \\
\text { terrains which are }\end{array}$ & & \multirow{5}{*}{$\begin{array}{l}\text { Terrain quality } \\
\text { and the } \\
\text { Topographic } \\
\text { characters guide } \\
\text { the Tsunami } \\
\text { DRR uses of } \\
\text { POS }\end{array}$} & $\begin{array}{l}\text { gathering points with } \\
\text { improved accessibility } \\
\text { and connectivity }\end{array}$ \\
\hline $\begin{array}{l}\text { sloping inwards the } \\
\text { inland increases the } \\
\text { speed of the wave }\end{array}$ & \multirow{2}{*}{$\begin{array}{l}\text { Ability to incorporate } \\
\text { the design features } \\
\text { which slow down and } \\
\text { regulate the wave as a } \\
\text { mitigation feature }\end{array}$} & & $\begin{array}{l}\text { - POS in flat terrain can be } \\
\text { used to slow down and } \\
\text { regulate the wave as a }\end{array}$ \\
\hline \multirow{3}{*}{$\begin{array}{l}\text { Lack of clear and } \\
\text { direct evacuation } \\
\text { routes connecting } \\
\text { mountainous terrain in } \\
\text { walking distance }\end{array}$} & & & $\begin{array}{l}\text { through the design } \\
\text { features }\end{array}$ \\
\hline & \multirow{2}{*}{$\begin{array}{l}\text { Availability of } \\
\text { mountainous terrain } \\
\text { which can be used as } \\
\text { emergency evacuation } \\
\text { points }\end{array}$} & & $\begin{array}{l}\text { Landscape treatments for } \\
\text { POS on terrains which } \\
\text { are sloping inwards the }\end{array}$ \\
\hline & & & inland \\
\hline
\end{tabular}

Terrain and Topographic characters guided allocation

$169 \times 93 \mathrm{~mm}(150 \times 150 \mathrm{DPI})$ 


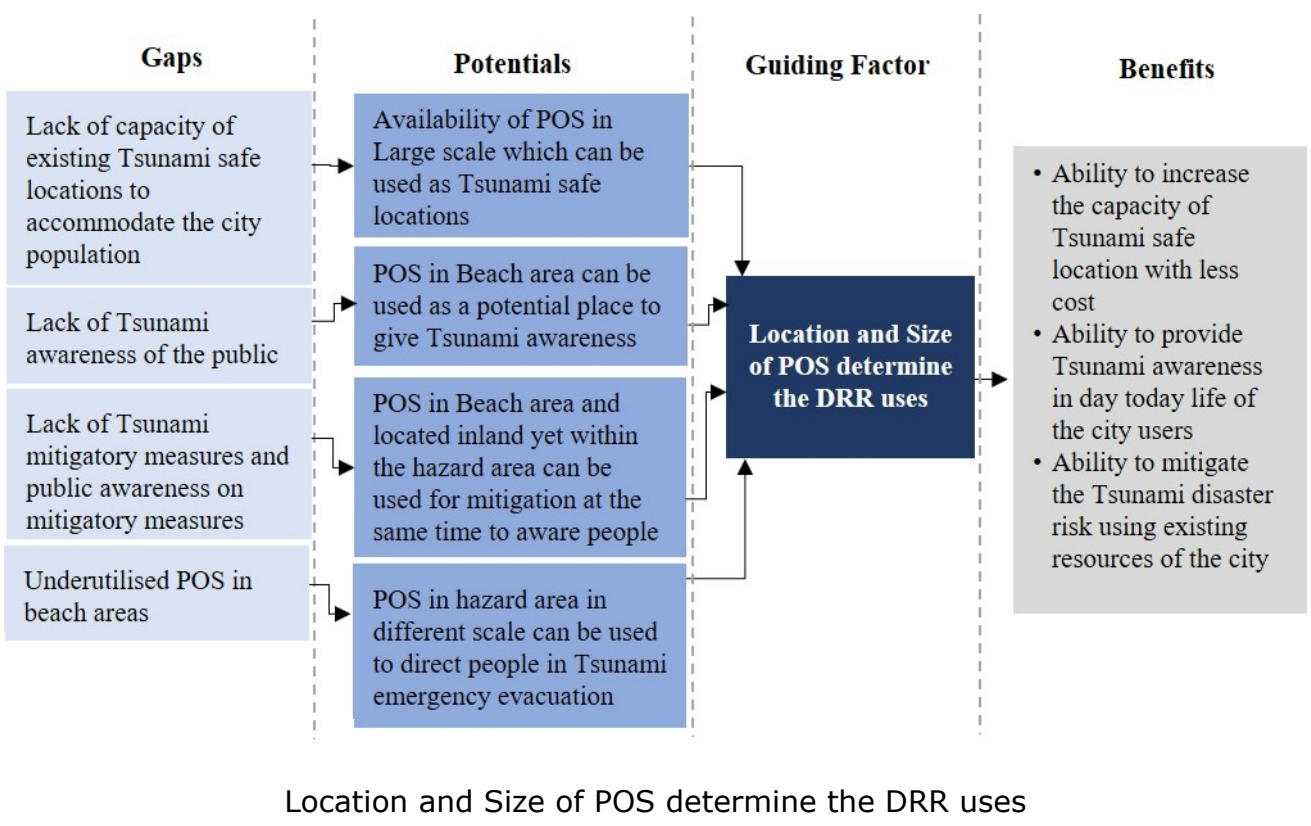

$172 \times 96 \mathrm{~mm}(150 \times 150 \mathrm{DPI})$ 


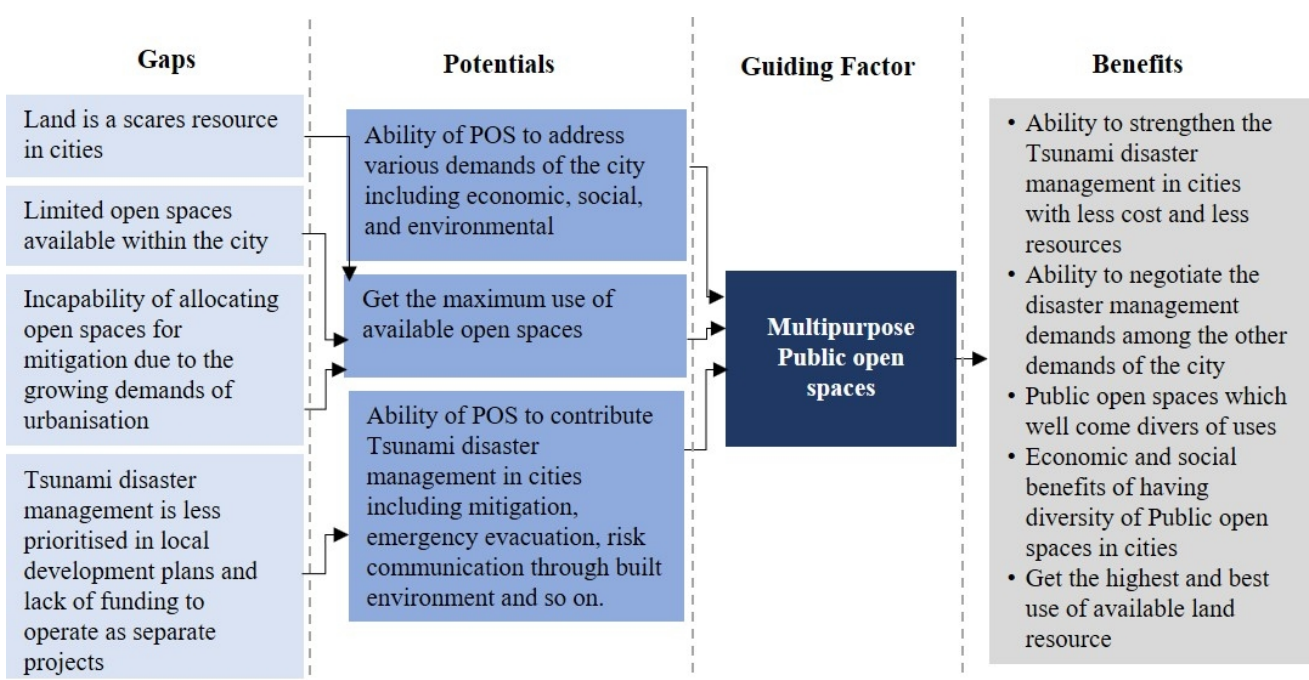

Multipurpose uses of POS

$181 \times 94 \mathrm{~mm}(150 \times 150 \mathrm{DPI})$ 


\begin{tabular}{|c|c|c|c|}
\hline Gaps & Potentials & Guiding Factor & Benefits \\
\hline $\begin{array}{l}\text { Some Public open spaces } \\
\text { are underutilised due to } \\
\text { the isolation }\end{array}$ & $\begin{array}{l}\text { Availability of POS in } \\
\text { different scales distributed in } \\
\text { different locations within the }\end{array}$ & \multirow{4}{*}{$\begin{array}{c}\text { Networking } \\
\text { Public open spaces } \\
\text { which work as a } \\
\text { Tsunami DRR } \\
\text { passage }\end{array}$} & \multirow{4}{*}{$\begin{array}{l}\text { - Benefits of disaster risk } \\
\text { sensitive planning } \\
\text { - Work as a system in } \\
\text { emergency evacuation } \\
\text { - Avoid traffic } \\
\text { congestions in } \\
\text { emergency evacuation } \\
\text { - Ability to use the } \\
\text { network to distribute } \\
\text { people among the safe } \\
\text { locations } \\
\text { - Effective usage of POS } \\
\text { with improved } \\
\text { accessibility } \\
\text { - Urban planning } \\
\text { benefits of Network of } \\
\text { POS }\end{array}$} \\
\hline $\begin{array}{l}\text { Lack of funding for } \\
\text { allocation of safe } \\
\text { locations }\end{array}$ & $\begin{array}{l}\text { Possibility of managing POS } \\
\text { as an interlinked system }\end{array}$ & & \\
\hline $\begin{array}{l}\text { Expected bottle neck } \\
\text { congestions due to the } \\
\text { lack of connectivity and } \\
\text { human nature of 'follow } \\
\text { the crowd' }\end{array}$ & $\begin{array}{l}\text { Depending on the terrain, } \\
\text { scale and location POS can } \\
\text { contribute to Tsunami disaster } \\
\text { management in various ways }\end{array}$ & & \\
\hline $\begin{array}{l}\text { Disadvantages due to the } \\
\text { poor linkage between } \\
\text { current spatial planning } \\
\text { with disaster management }\end{array}$ & $\begin{array}{l}\text { Disaster risk sensitive urban } \\
\text { planning }\end{array}$ & & \\
\hline
\end{tabular}

Networking POS works as a DRR passage

$184 \times 90 \mathrm{~mm}(150 \times 150 \mathrm{DPI})$ 